\title{
Leukoencephalopathy Associated with Severe COVID-19 Infection: Sequela of Hypoxemia?
}

\author{
(D) M. Lang, (DK. Buch, (DM.D. Li, (D)W.A. Mehan, Jr, (D)A.L. Lang, (D)T.M. Leslie-Mazwi, and (D).P. Rincon
}

\begin{abstract}
SUMMARY: There is increasing evidence to suggest that complications of coronavirus disease 2019 (COVID-19) infection are not only limited to the pulmonary system but can also involve the central nervous system. Here, we report 6 critically ill patients with COVID-19 infection and neuroimaging findings of leukoencephalopathy. While these findings are nonspecific, we postulate that they may be a delayed response to the profound hypoxemia the patients experienced due to the infection. No abnormal enhancement, hemorrhage, or perfusion abnormalities were noted on MR imaging. In addition, Severe Acute Respiratory Syndrome coronavirus 2 was not detected in the CSF collected from the 2 patients who underwent lumbar puncture. Recognition of COVID-19related leukoencephalopathy is important for appropriate clinical management, disposition, and prognosis.
\end{abstract}

ABBREVIATIONS: COVID-19 = coronavirus disease 2019; $\mathrm{PaO}_{2}=$ partial pressure of oxygen; SARS-CoV-2 = Severe Acute Respiratory Syndrome coronavirus 2; $\mathrm{MR}=$ magnetic resonance; $\mathrm{CT}=$ computed tomography; CSF $=$ cerebrospinal fluid

$\mathbf{T}$ here is mounting evidence that Severe Acute Respiratory Syndrome coronavirus 2 (SARS-CoV-2) can affect the central nervous system, with hematogenous spread or direct neural propagation via the olfactory pathway proposed as possible mechanisms of SARS-CoV-2 neurotropism. ${ }^{1}$ The angiotensin converting enzyme 2 receptor plays a role in the mechanism by which the SARS-CoV-2 gains cellular entry and is expressed in the brain. ${ }^{2,3}$ Furthermore, the SARS-CoV-2 virus has been detected in the CSF of a patient with coronavirus disease 2019 (COVID-19). ${ }^{4}$ Neurologic symptoms are commonly reported in patients with COVID-19 infection; a study from France reported that $91 \%$ of patients with COVID-19 infection demonstrated neurologic symptoms, while a study from China reported a lower prevalence of $36 \%{ }^{5,6}$ Moreover, there are case reports of encephalitis, including a case of hemorrhagic necrotizing encephalopathy, associated with COVID-19 infection. ${ }^{7-10}$ Recently, there is emerging evidence of white matter injury associated with COVID-19 infection in the form of demyelinating lesions and leukoencephalopathy without a clear etiology. ${ }^{11,12}$ Here, we report a case series of suspected white matter injury in patients with COVID-19 infection.

Received May 18, 2020; accepted after revision May 30.

From the Departments of Radiology (M.L., K.B., M.D.L., W.A.M., Jr, S.P.R.), Anesthesia, Critical Care, and Pain Medicine (A.L.L.), and Neurosurgery and Neurology (T.M.L.-M.), Massachusetts General Hospital, Harvard Medical School, Boston, Massachusetts. Please address correspondence to Min Lang, MD, MSc, Department of Radiology, MA General Hospital, 55 Fruit St, Boston, MA 02114; e-mail: mlang@mgh.harvard.edu

- Indicates open access to non-subscribers at www.ajnr.org

Indicates article with supplemental on-line table.

http://dx.doi.org/10.3174/ajnr.A6671

\section{CASE SERIES}

Our study was performed retrospectively, at a large, urban, academic medical center and was approved by the institutional review board with a waiver of informed consent. A total of 42 patients who tested positive for COVID-19 via real-time reverse transcription polymerase chain reaction underwent brain $\mathrm{MR}$ imaging, and the imaging was reviewed. Six patients were found to have imaging findings of leukoencephalopathy and were included in this study.

All 6 patients presented to our hospital for increased difficulty in breathing, and all without neurologic impairment at the time of presentation. The average age of the patients was 64 years (range, 60-76 years; 4 men and 2 women). No patients had a history of neurologic disease or were immunocompromised. One patient had brain MR imaging 1 year prior, which demonstrated minimal nonspecific white matter changes without other abnormalities. All 6 patients required intubation in the emergency department for hypoxic respiratory failure. The lowest recorded arterial oxygen level (partial pressure of oxygen $\left[\mathrm{PaO}_{2}\right]$ ) was between 46 and $66 \mathrm{~mm} \mathrm{Hg}$ during their hospital course, with an average of $55 \mathrm{~mm} \mathrm{Hg}$ (On-line Table). All 6 patients were weaned off sedation between admission days 9 and 24 when their respiratory status improved, with 2 patients successfully extubated. All patients exhibited altered mental status and neurologic symptoms between admission days 15 and 30 .

Five of the 6 patients underwent noncontrast-enhanced CT imaging first, with a mean time to CT of 23 days (range, 14-30 days) from date of admission. Four of the 5 CT 
studies were unremarkable, with only patient 2 exhibiting multiple bilateral hypodense lesions in the deep cerebral white matter (Fig 1).

All 6 patients eventually underwent MR imaging of the brain with a mean time to MR imaging of 26 days (range, 14-34 days) from date of admission. The mean duration between the $\mathrm{PaO}_{2}$ nadir and MR imaging was 22 days (range, 13-29 days). All MR imaging examinations performed at our institution included axial diffusion-weighted imaging $(b=1000)$, susceptibility-weighted

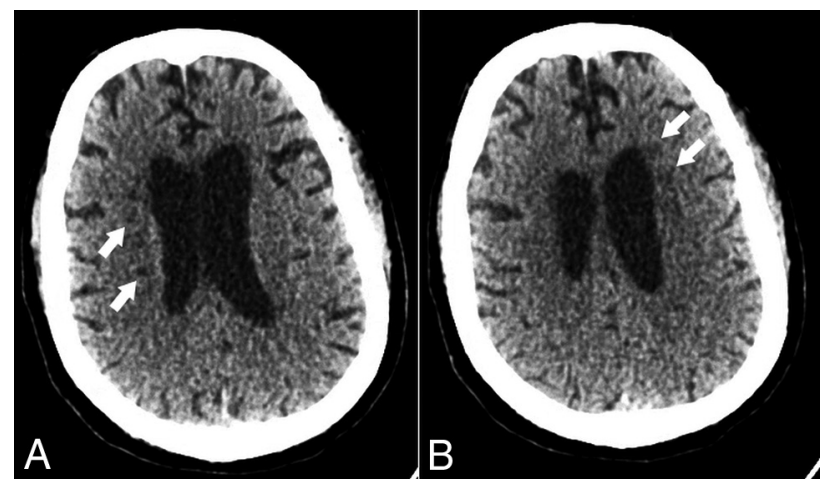

FIG 1. Head CT of a critically ill patient (patient 2) with COVID-19 infection. Axial CT images demonstrate multiple hypodense foci within the bilateral periventricular white matter (white arrows) without evidence of hemorrhage. imaging, axial T2 FLAIR, and axial T2-weighted imaging. Three patients had contrast-enhanced T1-weighted imaging, 2 patients had MRA, and 3 patients had arterial spin-labeling.

On MR images, all 6 patients exhibited symmetric T2 FLAIR hyperintense signal and restricted diffusion involving the deep white matter of both cerebral hemispheres, with relative sparing of the subcortical U-fibers (Figs 2 and 3). Additional sites of white matter involvement were also observed in the 6 patients: corpus callosum in patient 2 (Fig 2); middle cerebellar peduncles in patients $1,2,4,5$, and 6 (Fig 4); and corticospinal tracts in patients 2, 3 and 4 . On the fractional anisotropy map, focal areas of white matter tract disruption were observed only in patient 2 (Fig 2). No evidence of brain stem or basal ganglia involvement, mass effect, hemorrhage, or other acute findings was observed. Of the patients who also underwent contrast-enhanced MR imaging, MRA, or arterial spin-labeling, no abnormal gadolinium enhancement, vascular pathology, or perfusion abnormality was observed (Figs 4 and $5)$. The imaging findings of restricted diffusion with corresponding T2 FLAIR hyperintensity in the white matter are consistent with leukoencephalopathy.

\section{DISCUSSION}

Neurologic complications related to COVID-19 infection are not uncommon, but associated neuroimaging manifestations have

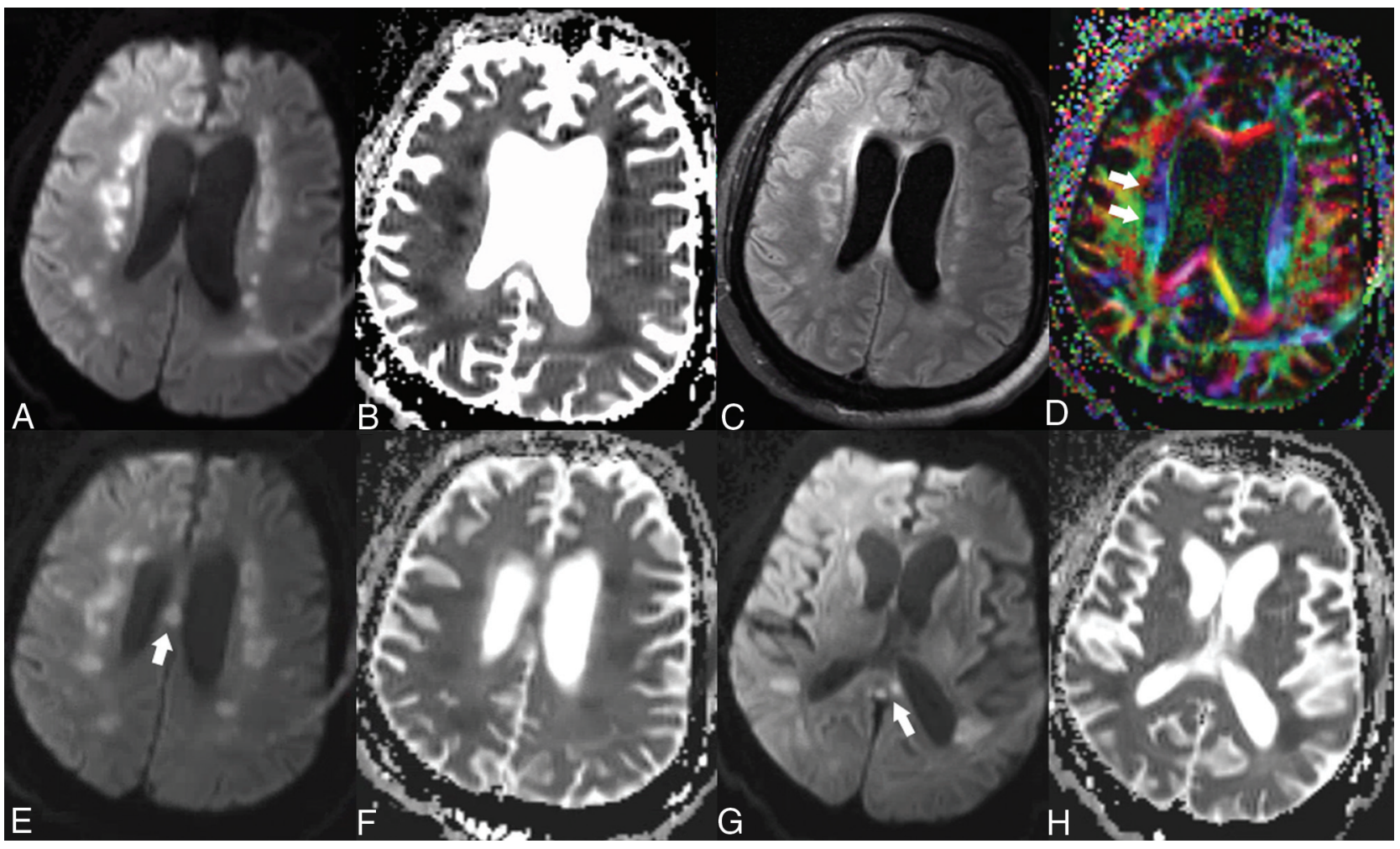

FIG 2. Brain MR images of a critically ill patient (Patient 2) with COVID-19 infection exhibiting impaired arousal, aphasia, and lethargy. $A$ and $B$, Paired axial DWI and ADC map show symmetric foci of restricted diffusion involving the deep white matter of both cerebral hemispheres. $C$, Axial T2/FLAIR image through the same level shows associated increased T2/FLAIR hyperintensity corresponding to the regions of restricted diffusion. $D$, Axial fractional anisotropy map shows focal disruption of white matter tracts in the regions of diffusion restriction (white arrows). $E$ and $F$, Paired axial DWI and ADC map show restricted diffusion of the body of the corpus callosum (arrow). G and $H$, Paired axial DWI and ADC map show restricted diffusion of the splenium of the corpus callosum (arrow). 


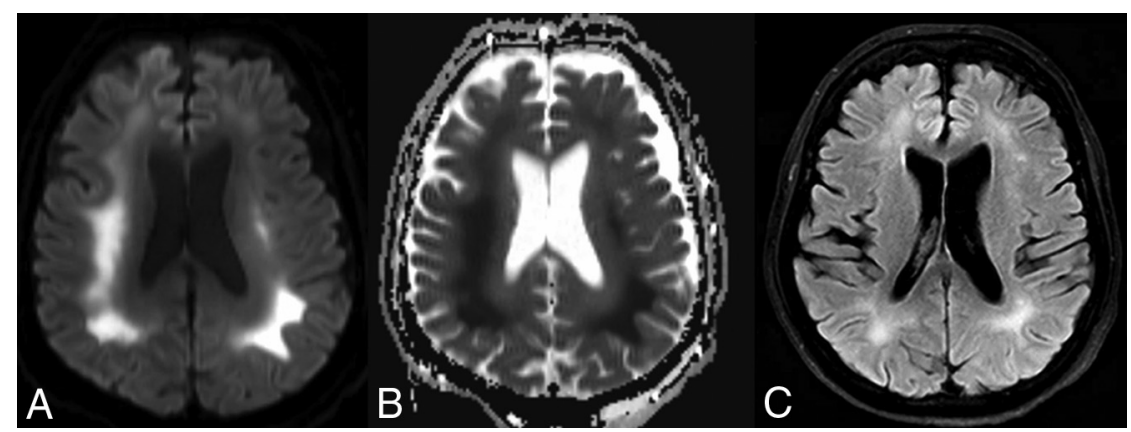

FIG 3. Brain MR images of a critically ill patient (patient 1) with COVID-19 infection exhibiting altered mental status. $A$ and $B$, Paired axial DWI and ADC map show symmetric restricted diffusion of the deep white matter of both cerebral hemispheres. C, Axial T2 FLAIR image through the same level shows associated increased T2 FLAIR hyperintensity corresponding to the regions of restricted diffusion.
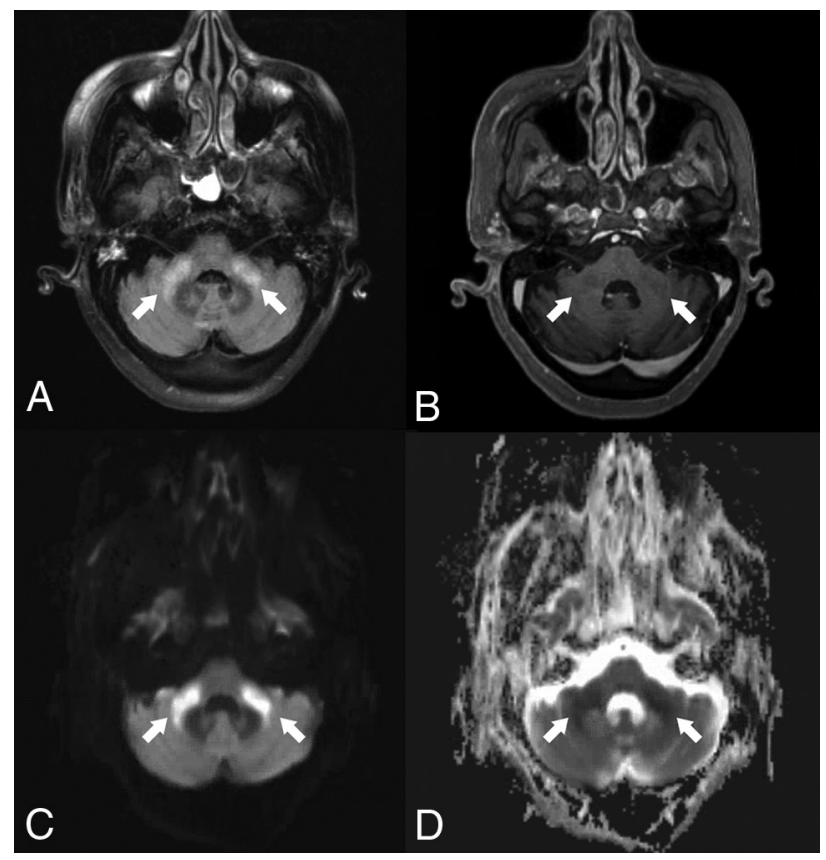

FIG 4. Brain MR images of a critically ill patient (patient 5) with COVID-19 infection exhibiting impaired arousal and diffuse hypertonicity. A, Axial FLAIR image shows increased T2 FLAIR signal in the bilateral middle cerebellar peduncles (arrows). B, Contrast-enhanced T1-weighted image shows absence of abnormal enhancement of the bilateral middle cerebellar peduncles (arrows). $C$ and D, Paired axial DWI and ADC map show corresponding restricted diffusion of bilateral middle cerebellar peduncles (arrows).

not been extensively investigated. ${ }^{5,7,10,13}$ Initial reported neuroimaging findings related to COVID-19 infection included infarction, hemorrhage, and encephalopathy. 5,7,13-15 Recently, leukoencephalopathy with intracranial microhemorrhages was reported. ${ }^{11}$ Specifically, the authors observed posterior predominant white matter FLAIR hyperintensity, posterior circulation hyperperfusion, and susceptibility signal in the corpus callosum. The mechanism underlying leukoencephalopathy in the setting of COVID-19 infection, however, remains unclear. While neurotropism has been proposed as an underlying cause for neurologic symptoms related to COVID-19 infection, there may be additional mechanisms at play. ${ }^{1}$ Specifically, the brain is sensitive to oxygen deprivation, and severe COVID-19 infection is known to be associated with hypoxemia. ${ }^{16}$ In our case series, we present evidence of white matter-specific injury, which may be the sequela of COVID-19related hypoxemia.

On MR imaging, all patients in our case series exhibited sparing of the subcortical U-fibers and brain stem, with relatively symmetric involvement of the deep cerebral white matter, which is reminiscent of delayed posthypoxic leukoencephalopathy. ${ }^{17}$ Severe cases of COVID-19 infection are associated with profound hypoxemia, and all 6 patients in our series required intubation and experienced marked hypoxemia. It has been postulated that prolonged or severe hypoxemia can lead to myelin sheath damage through dysfunction of the adenosine triphosphate-dependent enzymes responsible for myelin secretion and maintenance-a cycle of approximately every 23 days. ${ }^{18}$ Neurologic symptoms in all 6 patients were first detected between 14 and 23 days after the date of the lowest recorded $\mathrm{PaO}_{2}$. Furthermore, the mean duration between $\mathrm{MR}$ imaging and the $\mathrm{PaO}_{2}$ nadir was 22 days, which could be consistent with a posthypoxemic etiology.

Infection-related leukoencephalopathy due to neurotropism is also possible, and similar features have been reported with other infectious agents, including human immunodeficiency virus, human polyomavirus JC, and Borrelia burgdorferi (Lyme disease). ${ }^{17}$ SARSCoV-2, however, was not detected in the CSF samples of 2 patients in our series who underwent lumbar puncture, and no other abnormalities were noted in the CSF samples (On-line Table). ${ }^{17}$ There is the possibility of false-negative CSF findings as the sensitivity and specificity of SARS-CoV-2 detection in the CSF has not been established. Confirmation of tropism to the cerebral white matter by SARS-CoV-2 requires further pathology and postmortem investigation. Vascular and toxic/metabolic causes of leukoencephalopathy are also possible; however, the absence of perfusion abnormalities, infarction, hemorrhage, and the lack of clear toxin or medicationrelated culprits in these patients make these etiologies less likely. ${ }^{17}$ Finally, neural injury related to the cytokine storm syndrome has been proposed, with Poyiadji et $\mathrm{al}^{7}$ reporting neuroimaging findings of acute necrotizing encephalopathy in a case of COVID-19 infection. ${ }^{19}$ These imaging features, however, were absent in our case series but this may be related to differences in disease severity, imaging at different stages of the disease, or different underlying processes. Further investigation into the inflammatory response associated with neurologic injury in patients with COVID-19 infection is warranted.

There are several limitations of our case series, the first of which is the small number of patients. Second, only 1 patient had brain MR imaging 1 year prior, which showed minimal nonspecific white matter changes. The remaining 5 patients had no baseline imaging studies. However, given the normal neurologic status of the 6 


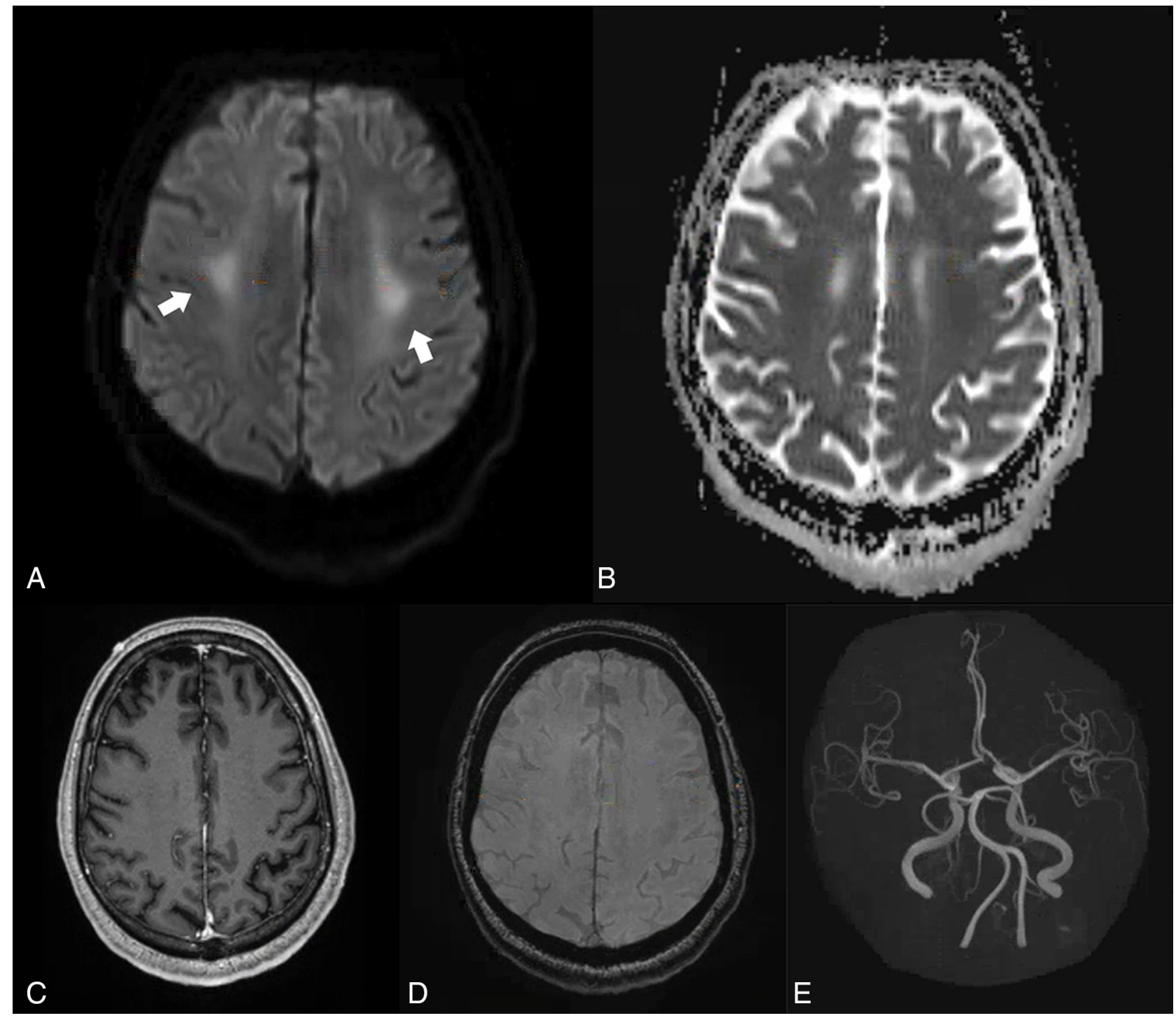

FIG 5. Brain MR images of a critically ill patient (patient 4) with COVID-19 infection exhibiting impaired arousal and left distal lower extremity paresis. $A$ and $B$, Paired axial DWI and ADC map show symmetric restricted diffusion of the bilateral perirolandic white matter (arrows). $C$, Axial contrast-enhanced T1-weighted image at the same level demonstrates no corresponding abnormal enhancement. $D$, Susceptibility-weighted image at the same level demonstrates no susceptibility effect to suggest hemorrhage. $E$, 3D reconstruction of the circle of Willis from time-offlight imaging demonstrates no vascular abnormality.

patients before admission, the white matter abnormalities seen in our case series were unlikely to be chronic in nature. Third, given the critical condition of these patients, serial imaging was not performed to assess the ongoing evolution of these neuroimaging findings. Larger cohort studies with standardized imaging sequences are required to better evaluate the spectrum of neuroimaging findings related to COVID-19 infection.

Recognition of a clinical syndrome is an initial step in deciphering disease mechanisms, introducing and testing therapeutic modalities, and ultimately modifying the course for improved patient outcomes. Health care providers should be aware of the potential for a COVID-19-related delayed leukoencephalopathy syndrome in patients infected with SARS-CoV-2 and displaying subacute neurologic deficits, despite improvement in respiratory status. The consequences of delayed post- hypoxic leukoencephalopathy can be severe, including both morbidity from chronic neurologic deficits and mortality. Further research is necessary to better understand this entity.

Disclosures: Karen Buch—UNRELATED: Employment: Massachusetts General Hospital. William A. Mehan, Jr-UNRELATED: Consultancy: Independent Review Committee member Kura Oncology, Comments: radiology reviewer for head and neck cancer clinical trial; Expert Testimony: medicolegal expert consulting work. Thabele M. Leslie-Mazwi-UNRELATED: Employment: Massachusetts General Hospital.

\section{REFERENCES}

1. Conde Cardona G, Quintana Pajaro LD, Quintero Marzola ID, et al. Neurotropism of SARS-CoV 2: mechanisms and manifestations. $J$ Neurol Sci 2020;412:116824 CrossRef Medline

2. Hoffmann M, Kleine-Weber H, Schroeder S, et al. SARS-CoV-2 cell entry depends on ACE2 and TMPRSS2 and is blocked by a clinically proven protease inhibitor. Cell 2020;181:271-80.e278 CrossRef Medline 
3. Xia H, Lazartigues E. Angiotensin-converting enzyme 2 in the brain: properties and future directions. J Neurochem 2008;107: 1482-94 CrossRef Medline

4. Hung EC, Chim SS, Chan PK, et al. Detection of SARS coronavirus RNA in the cerebrospinal fluid of a patient with severe acute respiratory syndrome. Clin Chem 2003;49:2108-09 CrossRef Medline

5. Mao L, Jin H, Wang M, et al. Neurologic manifestations of hospitalized patients with coronavirus disease 2019 in Wuhan, China. JAMA Neurol 2020 Apr 10. [Epub ahead of Print] CrossRef Medline

6. De Felice FG, Tovar-Moll F, Moll J, et al. Severe acute respiratory syndrome coronavirus 2 (SARS-CoV-2) and the central nervous system. Trends Neurosci 2020;43:355-57 CrossRef Medline

7. Poyiadji N, Shahin G, Noujaim D, et al. COVID-19-associated acute hemorrhagic necrotizing encephalopathy: CT and MRI features. Radiology 2020 Mar 31. [Epub ahead of Print] CrossRef Medline

8. Ye M, Ren Y, Lv T. Encephalitis as a clinical manifestation of COVID-19. Brain Behav Immun 2020 Apr 10. [Epub ahead of Print] CrossRef Medline

9. Zanin L, Saraceno G, Panciani PP, et al. SARS-CoV-2 can induce brain and spine demyelinating lesions. Acta Neurochir (Wien) 2020 May 4. [Epub ahead of Print] CrossRef Medline

10. Moriguchi T, Harii N, Goto J, et al. A first case of meningitis/encephalitis associated with SARS-Coronavirus-2. Int J Infect Dis 2020;94:55-58 CrossRef Medline

11. Sachs JR, Gibbs KW, Swor DE, et al. COVID-19-associated leukoencephalopathy. Radiology 2020 May 14. [Epub ahead of Print] CrossRef Medline
12. Kandemirli SG, Dogan L, Sarikaya ZT, et al. Brain MRI findings in patients in the intensive care unit with COVID-19 infection. Radiology 2020 May 8. [Epub ahead of Print] CrossRef Medline

13. Helms J, Kremer S, Merdji H, et al. Neurologic features in severe SARS-CoV-2 infection. N Engl J Med 2020;382:2268-70 CrossRef Medline

14. Oxley TJ, Mocco J, Majidi S, et al. Large-vessel stroke as a presenting feature of Covid-19 in the young. N Engl J Med 2020;382:660 CrossRef Medline

15. Jain R, Young M, Dogra S, et al. COVID-19 related neuroimaging findings: a signal of thromboembolic complications and a strong prognostic marker of poor patient outcome. J Neurol Sci 2020; 414:116923 CrossRef Medline

16. Marini JJ, Gattinoni L. Management of COVID-19 respiratory distress. JAMA 2020 April 24. [Epub ahead of Print] CrossRef Medline

17. Sarbu N, Shih RY, Jones RV, et al. White matter diseases with radiologic-pathologic correlation. Radiographics 2016;36:1426-47 CrossRef Medline

18. Beeskow AB, Oberstadt M, Saur D, et al. Delayed post-hypoxic leukoencephalopathy (DPHL): an uncommon variant of hypoxic brain damage in adults. Front Neurol 2018;9:708 CrossRef Medline

19. Mehta P, McAuley DF, Brown M, et al; HLH Across Speciality Collaboration, UK. COVID-19: consider cytokine storm syndromes and immunosuppression. Lancet 2020;395:1033-34 CrossRef Medline 